Outros Tempos, vol. 18, n. 32, 2021, p. 278-297. ISSN: 1808-8031

DOI: $\underline{\text { http://dx.doi.org/10.18817/ot.v18i32.858 }}$

\title{
O JORNAL PUBLICADOR MARANHENSE E A CONSTRUÇÃO DA GUERRA DO PARAGUAI 1865-1868 ${ }^{1}$
}

\author{
THE NEWSPAPER PUBLICADOR MARANHENSE AND THE SHAPING OF THE \\ PARAGUAYAN WAR 1865-1868
}

\section{EL PERIÓDICO PUBLICADOR MARANHENSE Y LA CONSTRUCCIÓN DE LA GUERRA DE PARAGUAY 1865-1868}

\author{
JOHNY SANTANA DE ARAÚJO \\ ORCID: http://orcid.org/0000-0003-3082-1785 \\ Doutor em História Social pela UFF \\ Professor da Universidade Federal do Piauí \\ Teresina/Piauí/Brasil \\ johnysant@gmail.com
}

\begin{abstract}
Resumo: Em 1865, quando o Império do Brasil acabava de concluir a vitoriosa intervenção usando o exército e a esquadra imperial no Uruguai, os ventos da guerra já estavam no horizonte, e a República do Paraguai colocava a sua máquina de guerra em marcha. Enquanto isso, nas províncias do Império se iniciava outra guerra, tão dura quanto a que o país travaria nos campos de batalha: a das redações dos jornais, dos editores e jornalistas comprometidos com a intensa propaganda da campanha deflagrada pelo país por seis longos anos. O presente artigo analisa o papel de um dos mais importantes jornais da província do Maranhão na época, o periódico Publicador Maranhense. O seu compromisso com o governo o caracterizou com um dos mais ativos órgãos de apoio a causa da guerra; portanto, o posicionamento de seu editor, de seus redatores, de suas matérias e a compreensão de sua linguagem são a tônica deste estudo.
\end{abstract}

Palavras-chave: Maranhão. Jornais. Guerra do Paraguai. Século XIX.

Abstract: In 1865, when the Brazilian Empire had just finished its victorious intervention using its army and imperial squadron in Uruguay, the winds of war were already blowing on the horizon, and the Republic of Paraguay was putting its own war machine to march. Meanwhile, in the provinces of the Empire another war was beginning, and it would be as harsh as the one the country would fight in the battlefield. This was a war fought in the newsrooms of the newspapers, involving editors and journalists engaged with the intense propaganda focusing on the campaign that took place throughout the whole country for six long years. This essay analyzes the role of one of the most important newspapers of the province of Maranhão at the time, the periodical Publicador Maranhense. The newspaper's allegiance with the government characterized it as one of the most active supporting pillars of the cause of the war; the position of its editor and its writers, as well as its news articles and the understanding of its language are the focus of this essay.

Keywords: Maranhão. Paraguayan War. Nineteenth Century.

Resumen: En 1865, cuando el Imperio de Brasil terminaba su victoriosa intervención utilizando las fuerzas del ejército y del escuadrón imperial en el Uruguay, los vientos de guerra ya se juntaban en el horizonte, y la República del Paraguay ponía en camino su máquina de guerra. Mientras tanto, en las provincias del Imperio empezaba otra guerra, quizás más dura que la que el país lucharía en el campo de batalla, y que se desarrollaría en las salas de redacción de periódicos, con los editores y periodistas comprometidos con la intensa propaganda de la campaña que se propagó por todo el país durante seis

\footnotetext{
${ }^{1}$ Artigo submetido à avaliação em abril de 2021 e aprovado para publicação em junho de 2021.
} 
Outros Tempos, vol. 18, n. 32, 2021, p. 278-297. ISSN: 1808-8031

largos años. Este ensayo analiza el papel de uno de los periódicos más importantes de la provincia del Maranhão en aquel tiempo, el Publicador Maranhense. Su compromiso con el gobierno lo caracterizó como uno de los órganos más activos para el apoyo a la guerra; las posiciones de su editor y de sus periodistas, sus artículos y la comprensión de su lenguaje son el foco de este estudio.

Palabras clave: Maranhão. Guerra del Paraguay. Siglo Diecinueve.

\section{Introdução}

A proposta deste artigo é estudar sobre um dos jornais mais importantes da província do Maranhão, que atuou na segunda metade do século XIX, o periódico Publicador Maranhense. O texto procura identificar a contribuição desse jornal no processo de arregimentação da população para a formação dos Corpos de Voluntários da Pátria, nos anos de 1865-1866, ou seja, buscar em suas páginas as notícias e a divulgação sobre a guerra, que o Império do Brasil travava contra o Paraguai, e a evolução e o percurso desse conflito, e indicar como suas notícias influenciaram no processo de formação dos Corpos de Voluntários da Pátria ${ }^{2}$.

A Guerra do Paraguai pode ser entendida pelos historiadores como o marco maior do apogeu do Império do Brasil como uma potência regional ${ }^{3}$. A Guerra do Paraguai, de 1865 a 1870, determinou o percurso que o país seguiria. Muito se tem escrito sobre a perspectiva central da guerra, as questões das relações internacionais, mas, nos últimos anos, a perspectiva de estudar os efeitos da guerra pelas notícias em nível regional se tornou uma prática mais comum, e vários estudos sobre o impacto das notícias da guerra nas províncias começaram a surgir ${ }^{4}$.

O presente artigo visa, portanto, ampliar os estudos sobre os jornais no Maranhão no contexto da Guerra do Paraguai, pois foi identificado que ainda há poucos estudos sobre a influência dos jornais em uma província distante como a do Maranhão na construção de uma consciência da guerra, bem como sobre a conjunção de interesses dos jornais e seus editores com o governo imperial do Brasil. Foi possível descobrir a construção de uma diversidade de tramas políticas que também desafiam e complementam os sentidos do exercício das agremiações políticas na referida província do Maranhão.

\footnotetext{
${ }^{2}$ O Corpo de Voluntários da Pátria foi uma entidade criada por meio do decreto imperial $\mathrm{n}^{\circ} 3.371$, de 7 de janeiro de 1865, que visava regularizar o voluntariado para a guerra contra o Paraguai. Ver: (SALLES, 1990); ver também, como obra de referência em diversos volumes: (DUARTE, 1981).

3 Sobre a projeção da guerra e do Brasil nas relações internacionais, ver: (BANDEIRA, 2012). Sobre os antecedentes da guerra, ver: (ARAÚJO, 2017).

${ }^{4}$ No exterior, esse fenômeno foi observado por Thomas Whigham em seu trabalho sobre a Guerra do Paraguai, ver: (WHIGHAM, 2018, p. 21).
} 
Outros Tempos, vol. 18, n. 32, 2021, p. 278-297. ISSN: 1808-8031

Os jornais representam paradigmas para se compreender a expansão da notícia no século XIX no Brasil, são fontes riquíssimas, pois colaboraram na construção de um imaginário social e político.

No século XIX, a mídia impressa era dominante, mas o período da segunda metade desse século é crucial porque representa a vitória do comercialismo na imprensa e sua fidelidade à política - tudo isso durante uma era de expansão da revolução industrial e, posteriormente, ao estabelecimento do Estado Nação, que se fundiram com o mundo de então. No processo, as características centrais do jornalismo tornaram-se mais evidentes, junto com as bases para a expansão das ideias.

A tecnologia influenciou a extensão e a velocidade com que as informações eram transmitidas globalmente, bem como a apresentação e a natureza do conteúdo. Os jornais representavam um veículo para a liberdade e agiam como vigilantes ou apoiadores do governo, enquanto a luta pela liberdade de expressão se tornava parte de um processo de integração do jornalismo à estrutura capitalista.

Já na década de 1860 os jornais nas províncias do Norte se tornaram pelo menos tão importantes quanto os do Sul, como um emblema de como se tornar moderno, não apenas na arena política, mas também nas esferas econômica, social e educacional.

A Guerra do Paraguai ou Guerra da Tríplice Aliança, como também foi conhecida, pode ser considerada como um marco fundante na construção dos Estados Nacionais na América do Sul, a sua narrativa ao longo dos anos foi cristalizada por uma extensa produção historiográfica, que pode ser tomada segundo uma perspectiva diversa ${ }^{5}$. A partir de desdobramentos teóricos metodológicos mais recentes, a compreensão da Guerra do Paraguai por meio dos estudos sobre os jornais e sua participação na construção das notícias sobre o conflito, tornou-se mais comum ${ }^{6}$.

Os jornais tiveram uma relevância significativa na projeção da guerra, conseguindo estabelecer uma conexão entre o Sul e as províncias, e seu papel, que já era importante na primeira metade do século XIX, na segunda metade do século adquiriu importância crucial, já manifestada pela ampla cobertura que os periódicos haviam dado a

\footnotetext{
${ }^{5}$ Há pelo menos três perspectivas de compreensão sobre a guerra: (i) uma historiografia oficial, surgida no pósguerra e cristalizada por trabalhos de memorialistas, cuja grande relevância se constitui na própria originalidade documental; (ii) uma historiografia revisionista, que surge no final da década de 1960 do século XX, encastelada nas universidades, defensora da ideia de intervenção inglesa e do projeto de destruição total do Paraguai pelos países signatários do Tratado da Tríplice Aliança; e, finalmente, (iii) uma historiografia mais recente, surgida em fins dos anos 90, que trata o tema sob a perspectiva de uma nova história política, militar e das relações internacionais, que valoriza a ideia da formação dos estados nacionais na América do Sul. Sobre a historiografia da Guerra do Paraguai, ver: (MAESTRI, 2009).

${ }^{6}$ Sobre os jornais e a Guerra do Paraguai, ver: (PAULA, 2020).
} 
Outros Tempos, vol. 18, n. 32, 2021, p. 278-297. ISSN: 1808-8031

outros conflitos do exterior ou a situações de conflito em que o Brasil havia tomado parte, como em $1852^{7}$. Na Europa, os jornais cobriram vários conflitos, como o jornal Times, de Londres, que havia estendido uma extensa linha de telégrafos da zona de guerra na Crimeia até o ocidente para manter os seus leitores informados. Nos Estados Unidos, a cobertura da guerra da Secessão também havia sido notabilizada por órgãos como New York Times e o New York Herald. Foi a época da empresa jornalística com surgimento, inclusive, das grandes agências de notícias, como a Associated Press e a Reuters (BERNARDO; LEAO, 2013, p. 341).

A guerra de um modo geral havia se tornado pauta principal das notícias na Corte e nas demais províncias do Império, projetando sentidos e construindo discursos favoráveis ao conflito. Na Corte existia o Jornal do Commercio, o Diário do Rio de Janeiro e o Correio Mercantil, jornais detentores de grande influência política e comercial, que divulgavam sobre os desdobramentos da guerra e sobre a mobilização da sociedade ${ }^{8}$. Em São Paulo, por exemplo, os jornais da época fizeram com que fosse despertado, em parte da população, uma reação favorável à guerra, ao ponto de atenderem à convocação do governo (MORSE, 1970, p. 195-197).

Os jornais do Rio Grande do Sul, do Pará, do Piauí, do Ceará, de Pernambuco e da Bahia também divulgavam sobre a guerra e a mobilização em suas províncias; suas edições eram enviadas ao Maranhão, que eram transcritas pelos redatores e, em troca, as edições locais eram enviadas às províncias irmãs. Não havia um centro do qual irradiaria as notícias, mas, notadamente, o Rio de Janeiro se constituía num grande referencial, mas não o único. Assim, as províncias que mantinham trocas de jornais promoviam uma circularidade nas informações para além dos correspondentes que enviavam notícias do sul. A propagação das notícias da guerra era então possível graças à existência de redes de comunicação formadas pelos jornais da época, ainda incipientes, mas com abrangência nacional (SOARES, 2003, p. 6).

No Maranhão, quanto aos jornais, um dado importante se refere a como a divulgação da guerra contra o Paraguai acabou operando um intenso mecanismo de mobilização da sociedade que, para além da informação, significava criar um instrumento com os fins de promover o alistamento para a guerra e para o fortalecimento do exército, que já se encontrava em campanha no Uruguai desde 1864. Tais mecanismos foram utilizados de

\footnotetext{
7 Intervenção brasileira na Argentina para depor Juan Manoel Rosas em 1852. Sobre a intervenção, ver: (GANDIA, 2019).

${ }^{8}$ Sobre a projeção dos jornais na Corte, ver: (SILVEIRA, 2014).
} 
Outros Tempos, vol. 18, n. 32, 2021, p. 278-297. ISSN: 1808-8031

forma a criar um sentimento ideário de nação em armas. Nesse sentido, o trabalho, portanto, tem como objetivo fazer uma leitura e interpretação do jornal Publicador Maranhense, da cidade de São Luís do Maranhão.

A cidade de São Luís, durante a década de 60 do século XIX, congregava elementos não só do Partido Liberal, que era a situação naquele momento, mas também do Conservador e da Liga Progressista, cujas lideranças eram representadas por vários políticos na Corte, através da câmara e do senado. Alguns se tornaram ativos agentes do Império e atuavam junto do Conselho de Estado. Muitos eram jornalistas por vocação e em grande medida eram correspondentes dos jornais na província. No caso do Publicador Maranhense, se fazia representar por figuras diversas da conciliação, segundo Reis,

Da década de 1860 até o final do Império há uma alternância mais clara entre grupos políticos mais definidos. O período de 1862 a 1868, de ascensão da Liga Progressista no ambiente político da Corte, favoreceu o grupo liberal da Província, que predominou nas eleições gerais por três legislaturas e conseguiu a nomeação de dois senadores (Francisco Furtado e Marcelino Nunes Gonçalves). (REIS, 2007, p. 61).

Essa era uma época áurea da política e do jornalismo no Império e nas províncias, bem diferente da primeira metade do século XIX, quando os diversos grupos políticos travavam uma luta dura por influência e por poder, era uma época de refrega, tal como foi observado por João Francisco Lisboa, quando procurou traçar críticas sobre os embates políticos entre conservadores e liberais, que operavam uma imprensa tendenciosa que Lisboa julgava ser tipicamente de mau gosto,

[...] as mais imundas alimárias e sevandijas já não podem dar nomes que bastem para designá-los, a eles e aos seus periódicos, os cangambás, jaburus, bacuraus, muruçocas, papistas, sururus, guaribas e catingueiros. Assim os partidos vão buscar nas suas pretendidas tendências e princípios, nos ciúmes de localidade, nas disposições antimetropolitanas, na influência deste ou daquele chefe, desta ou daquela família e eis aí a rebentar de cada clube ou coluna de jornal, como do cérebro de Júpiter, armados de ponto em branco, o partido liberal, o conservador [...]. (LISBOA, 2004, p. 146).

A existência da imprensa no Brasil estava condicionada, antes de tudo, à dependência de oscilações partidárias, graças a alguma tolerância, mas principalmente, ao favoritismo partidário. Sobre a existência de uma população consciente e ilustrada, capaz de elaborar alguma noção de opinião pública aceitável e consciente, havia literatos no Império, como José de Alencar, que viam com pessimismo e desesperança a sociedade brasileira que julgava ser inculta, insensível, desperdiçada na indolência ou submetida pela ignorância, 
Outros Tempos, vol. 18, n. 32, 2021, p. 278-297. ISSN: 1808-8031

impedida de usufruir as vantagens da livre circulação do pensamento (SOARES, 2003, p. 12). Por outro lado, os jornais já se apresentavam como grandes difusores de opinião e sua relação com as forças políticas eram profundas, uma continuação aprimorada da primeira metade do século XIX.

Por ocasião da guerra com o Paraguai, houve uma intensificação dessa relação, de fato situações conflituosas anteriores envolvendo contendas do país com seus vizinhos, no caso, com a Argentina, e a própria questão Christie já havia demonstrado a associação de interesses entre o estado e os jornalistas ${ }^{9}$.

Nesse ambiente, podemos entender que os conceitos emitidos pelo jornal Publicador Maranhense impactavam junto a "boa sociedade ludovicense"10. Mais ainda, como importante campo de vivência cultural, analisar a forma como a propaganda da Guerra do Paraguai chegava às camadas populares é significativo para compreender como o erudito e o popular se cruzam.

O jornal Publicador Maranhense surgiu em meados de 1842, no mês de julho. Era um órgão oficial do governo, até 1862 tinha uma periodicidade de três vezes por semana e, após esse período, passou a ser diário. Durante a sua existência passaram por sua redação vários jornalistas de concepções políticas variadas, alguns eram notáveis. Até 1855 era redigido por João Francisco Lisboa, em 1856 Sotero dos Reis tomou a direção da redação, onde continuou até 1861. A partir desse ano, seu redator foi Temístocles Aranha, que permaneceu no periódico até fundar o seu próprio jornal, $O$ Paiz, em 1863, sendo substituído por Ovídio da Gama Lobo, que ficou até o início de 1864. Por todo esse ano, o Publicador Maranhense foi redigido por Antônio Henriques Leal. Em 1865, entrou para a redação Felipe

\footnotetext{
${ }^{9}$ Em linhas gerais o desentendimento entre o Império do Brasil e o Império Britânico teve início em fins de 1862, quando a Grã-Bretanha iniciou represálias contra o Brasil que levaram à ruptura das relações diplomáticas entre os dois países no ano seguinte. As represálias decorreram de dois incidentes: primeiro, o navio inglês HMS Prince of Wales havia naufragado na costa do Rio Grande do Sul, tendo a sua carga saqueada, o então ministro inglês Willian Dougal Christie reclamou que as autoridades não haviam dado a devida assistência; um segundo entrevero se deu quando três oficiais do navio inglês HMS Forte foram aprisionados pela polícia no Rio de Janeiro, em decorrência de algazarras. Na ocasião, Willian Christie mais uma vez protestou afirmando que o ato consistia um insulto à marinha de Sua Majestade, e deu ordens aos navios de guerra da Marinha Real para que apressassem navios brasileiros fundeados na baia de Guanabara, exigiu desculpas formais do governo brasileiro e cobrou uma indenização pela perda da carga do navio no Rio Grande do Sul. Diante da resposta negativa, o imperador Pedro II decidiu romper as relações diplomáticas com a Inglaterra. Houve uma mediação da questão, feita pelo rei Leopoldo II, da Bélgica. A decisão foi favorável ao Brasil, em 1863. A relação diplomática entre Brasil e Inglaterra permaneceu rompida por mais dois anos, sendo restabelecida apenas em 1865, quando o novo ministro britânico para o Brasil, Edward Thornton, apresentou suas credenciais ao imperador durante a sua visita ao Rio Grande do Sul, no contexto da guerra do Paraguai. Há estudos dedicados às razões dos reais motivos da contenda entre os dois países que extrapolam a atuação do diplomata Willian Christie, cujo ponto alto seria as questões tarifárias e as pressões inglesas pela abolição do tráfico negreiro, que havia gerado desgaste entre os dois países e se arrastava desde a década de 1850. Ver: (RÉ, 2019). Ver também o trabalho clássico de Richard Graham sobre a questão: (GRAHAM, 1962).

${ }^{10}$ Sobre a noção de boa sociedade, ver: (MATTOS, 2004).
} 
Outros Tempos, vol. 18, n. 32, 2021, p. 278-297. ISSN: 1808-8031

Franco de Sá e, em 1866, já era redigido por empregados da Secretaria de Governo (RAMOS, 1992, p. 94), tendo como editor o jornalista João da Mata de Morais Rego.

Quando a redação foi ocupada por Henriques Leal e Felipe Franco de Sá, o Publicador Maranhense teve um aumento significativo de artigos que abordavam questões sobre as finanças da província, mas, sobretudo, artigos sobre questões políticas, que tratavam sobre as leis encetadas na Assembleia Provincial; a sua condição de ser um órgão oficial respaldava o governo (SERRA, 2001, p. 30).

O Publicador Maranhense era o principal órgão de divulgação do governo provincial. Para além do referido periódico, é possível verificar a existência de outros jornais, igualmente representativos de agremiações políticas, como A Coalição e $O$ Paiz, que também eram exemplos claros de dedicação da imprensa na mobilização para a guerra. Segundo Viveiros, este último “[...] tomou à sua conta a propaganda da ideia. Publicava nomes dos voluntários quando chegavam do interior, quando eram inspecionados e alistados, louvandoos a coragem e patriotismo" (VIVEIROS, 1954, p. 359).

Em 1886, o Publicador Maranhense encerrou suas atividades, fundindo-se ao $O$ Paiz para formar um novo jornal. Ambos circularam durante toda a Guerra do Paraguai. Segundo Jeronimo de Viveiros, em 25 de janeiro de 1886, “[...] desaparecia o 'O Paiz', órgão do comércio, para surgir o 'O Paiz', jornal político” (VIVEIROS, 1954, p. 364).

Com base na análise de artigos e notícias, debates, artigos de jornais, correspondências, livros e anúncios textuais no jornal Publicador Maranhense, entre outros documentos históricos, foi possível descobrir que na província do Maranhão a ideia do conflito surgira como um eixo de expansão de ideias em prol da participação da província na guerra; portanto, estudar a manifestação do jornal significa entender a própria lógica da guerra para os maranhenses e que a sua contribuição seria representada pelo seu tributo e sangue.

\section{A construção da guerra nas páginas do Publicador Maranhense}

Quando a guerra no Prata se iniciou, os jornais e seus editores, de um modo geral, procuraram exaltar as ações do Império na região. Nas províncias havia um clima favorável à política brasileira no Prata, estabelecendo uma ideia de que o público estava apoiando a política externa do Império e que a guerra era um desafio que gerava um sentimento de euforia coletiva; o frontispício do jornal Publicador Maranhense, de 20 de janeiro de 1865, estampava essa ideia ao divulgar o sentimento capturado por João da Mata de Morais Rêgo, editor do jornal, segundo o qual informava: 
Outros Tempos, vol. 18, n. 32, 2021, p. 278-297. ISSN: 1808-8031

Como brasileiros, enchemo-nos de orgulho e sentimos [...] prazer no contemplar o enthusiasmo que pela guerra se vae desenvolvendo nas províncias do sul d'esta [...] toda a população parece animada por um só pensamento [...] apprescata-se a fazer o serviço militar - a marchar para o campo da guerra ${ }^{11}$.

Nessa, entre tantas outras representações, nos é possível identificar o amplo poder da propaganda dos meios jornalísticos a serviço do governo, no sentido de criar uma sensação de entusiasmo, tão necessária ao objetivo do alistamento voluntário que seria lançado pouco tempo depois.

Nessa mesma edição, o jornal Publicador Maranhense divulgou ainda a respeito das reuniões organizadas pelos membros da comissão da praça, da qual tomou parte várias pessoas influentes, jornalistas, entre eles, Felipe Franco de Sá, Antônio Henriques Leal, Temistocles Aranha e Gentil Braga, em que foi discutida a organização do voluntariado. Estavam todos amplamente envolvidos com a propaganda a favor da guerra.

No dia 23 de janeiro de 1865, o Publicador Maranhense informou que as primeiras reuniões haviam acontecido no Teatro, no dia 21 de janeiro daquele ano. Também relatou sobre a convergência por parte dos que estiveram no encontro, estando inclusive presentes membros de diferentes camadas da sociedade, em uma grande confraternização de cidadãos, segundo afirmou o jornal:

Não foi em vão o apello que se fez ao patriotismo dos brasileiros residentes nesta cidade. Ante-hontem acudiram elles em grande numero ao salão do theatro, sem distincção de opiniões, sem distincção de classes.

Dilatou-se nos o coração do prazer e enthusiasmo no contemplar o espetáculo grandioso e raro da fraternização de tantos cidadãos [...] No campo da guerra há só um (arroio) uma tenda, um exército, um peito, e um braço - o do brasileiro que acesso no puro amor da pátria estremecce por ela [...] E havera brasileiros tam degenerado que assim não pense, que não avalheie por isto? Não crermos, e a reunião do dia 21 é a prova mais clara e completa disto ${ }^{12}$.

Segundo consta, jornalistas, como Henriques Leal, acreditavam que essa ideia de euforia coletiva se dava porque a perspectiva da guerra estava produzindo um efeito desejado e necessário, e que ainda estava despertando nos brasileiros, o que ele chamou de sentimento do amor à pátria para defender o Brasil (LEAL, 1987, p. 343). Aparentemente, poderia haver

\footnotetext{
${ }^{11}$ Publicador Maranhense, n. 16, 20 jan. 1865. p. 1. Biblioteca Pública Benedito Leite. São Luís, Maranhão. Seção de Periódicos, rolo 94.

${ }^{12}$ Publicador Maranhense, n. 18, 23 jan. 1865. p. 2. Biblioteca Pública Benedito Leite. São Luís, Maranhão. Seção de Periódicos, rolo 94.
} 
Outros Tempos, vol. 18, n. 32, 2021, p. 278-297. ISSN: 1808-8031

uma justificativa para as manifestações de indignação que se deram no país, uma vez que havia ocorrido a invasão das fronteiras do Brasil. Sobre uma tomada de posição da população, o jornal Publicador Maranhense cobrava:

A honra nacional e a integridade do Império, esses caros penhores de um povo livre e independente, exigem imperiosamente o concurso de todos os brasileiros para a manutenção da guerra em que nos achamos empenhados com as repúblicas do Uruguai e Paraguai ${ }^{13}$.

Os jornais, de todo modo, trabalharam de forma a criar no imaginário dos moradores da província, uma ideia de patriotismo de três formas: em primeiro lugar, por alimentar semanalmente a província com informações sobre conflitos em outros países, bem como sobre as intervenções que o governo brasileiro preparava para fazer em nome da sua segurança, o que de certa forma acabou criando o ambiente para uma possível guerra; em segundo lugar, com a guerra já declarada, procurou sempre mostrar o Brasil como uma nação que havia sido agredida e invadida e que precisava recuperar a honra e os territórios conquistados pelo inimigo; e, finalmente, por mostrar que em outras províncias havia sempre voluntários dispostos a se oferecerem para a guerra, demonstrando dessa maneira que tal atitude era uma contribuição de coragem.

Dentro dessa conjuntura, houve de igual forma a preocupação com a desconstrução da imagem do presidente Solano Lopez, desqualificando sua conduta por haver desafiado aos países da região do Prata, mostrando-o como um tirano louco. Já em janeiro de 1866, o Publicador Maranhense divulgou informação referente a um ofício que Solano Lopez havia enviado ao general Mitre, comandante chefe dos exércitos aliados, sobre a possibilidade de paz, intitulado: "Lopez diverte-se". Segundo o jornal, o ofício era “[...] uma peça irônica e disfarçada que provocaria riso se não excitasse a indignação. Não há exemplo na história de tanta aceleratriz, unida a tanta petulância. $\mathrm{O}$ dictador do Paraguay mofa de todas as idéias nobres e de todos os sentimentos honestos [...]"14.

Como a Guerra do Paraguai foi um conflito que promoveu uma ampla mobilização nacional, a imprensa trabalhou paralelamente com o governo imperial e provincial, no sentido de criar uma ideia de unidade nacional em torno de um inimigo internacional, o Paraguai. No entanto, é de se observar que esse comportamento de busca por uma unidade nacional, apesar de ser algo recente no Brasil, era típico daquele momento em

\footnotetext{
13 Publicador Maranhense, n. 32, 9 fev. 1865. p. 2. Biblioteca Pública Benedito Leite. São Luís, Maranhão. Seção de Periódicos, rolo 94.

14 Publicador Maranhense, n. 10, 13 jan. 1866. p. 2. Arquivo Público do Estado do Maranhão. São Luís, Maranhão. Seção de Periódicos.
} 
Outros Tempos, vol. 18, n. 32, 2021, p. 278-297. ISSN: 1808-8031

outros países que passavam pelo processo de formação e consolidação de seus estados nacionais. No Brasil, os mais diversos segmentos da sociedade (entre intelectuais, artistas e jornalistas) estavam trabalhando há certo tempo em conjunto com o governo imperial, para criar um clima favorável a qualquer intervenção que o governo brasileiro viesse a realizar.

No Maranhão, o Publicador Maranhense também procurava dar notícias sobre os acontecimentos no exterior. Na edição de 20 de janeiro de 1865, publicou o discurso do presidente dos Estados Unidos no Congresso, sobre o desenrolar da guerra contra os confederados, dando destaque para a fala de Lincoln, de que: “[...] a guerra não cessará até a inteira submissão dos Estados do Sul. Diz mais que não acceitará proposição de paz que não sobre a base do restabelecimento da União"15.

As notícias da guerra civil americana, publicadas nos jornais que lembravam constantemente uma das razões desse conflito - a libertação dos escravos nos estados confederados -, também exerciam alguma influência. Por exemplo, o jornal Publicador Maranhense, na edição do dia 2 de janeiro de 1865, trazia as seguintes informações sobre a Guerra da Secessão: "Na América do Norte prosseguiu com mais encarniçamento essa guerra de quatro annos entre nortistas e sulistas, entre os federais que pugnam pela emancipação [dos escravos] e os confederados que defendem seus interesses" ${ }^{" 16}$. Isso é bastante revelador da capacidade da expansão das ideias proporcionadas pela informação do jornal, em uma província com alto índice de analfabetismo. O princípio de circularidade da informação também teria facilitado o alcance da notícia, propiciado pela leitura em espaços coletivos.

Em janeiro de 1865, o jornal Publicador Maranhense também começou a divulgar sobre o surgimento dos primeiros voluntários do Maranhão, ao noticiar que o "[...] Capitão do Corpo de Guarnição da Província do Maranhão, Augusto César Bittencourt, havia se oferecido para marchar para a guerra que o Brasil mantinha com as repúblicas do Uruguai e Paraguai" 17 . A ideia do voluntariado estava se ampliando naquele momento e, paralelamente, o estado imperial já havia instituído os regulamentos para organizá-lo.

Uma peça fundamental para essa organização e para o fortalecimento das tropas durante a campanha foi o estabelecimento do Decreto 3.371, de 7 de janeiro de 1865, que criava os Voluntários da Pátria. A imprensa toda noticiou e o Publicador Maranhense, de 28

\footnotetext{
15 Publicador Maranhense, n. 16, 20 jan. 1865. p. 1. Biblioteca Pública Benedito Leite. São Luís, Maranhão. Seção de Periódicos, rolo 94.

${ }^{16}$ Publicador Maranhense, n. 1, 2 jan. 1865. p. 1. Biblioteca Pública Benedito Leite. São Luís, Maranhão. Seção de Periódicos, rolo 94.

17 Publicador Maranhense, n. 17, 21 jan. 1865. p. 2. Biblioteca Pública Benedito Leite. São Luís, Maranhão. Seção de Periódicos, rolo 94.
} 
Outros Tempos, vol. 18, n. 32, 2021, p. 278-297. ISSN: 1808-8031

de janeiro de 1865, divulgou o edital da Secretaria Militar, informando sobre o decreto dos Voluntários da Pátria, dando conhecimento que:

Por ordem de S. Exe o Sr. presidente da província fica aberta a inscrição de voluntários a quem serão concedidas todas as vantagens de que trata o decreto $\mathrm{n}^{\circ} 3.371$ de 7 do corrente ano, sem outra formalidade alem da simples apresentação do voluntário nesta repartição e lançamento de seu nome em livro próprio depois de averiguações acerca das condições exigidas no predicto decreto ${ }^{18}$.

No mesmo edital é feita uma conclamação do governo: "O mesmo Exm. Sr. Apella para o patriotismo dos maranhenses tão interessados como o governo Imperial em sustentar a dignidade do Paiz [...]"19.

A propaganda de guerra por parte do governo era feita através de conclamações, discursos e convocações e, na província do Maranhão, a imprensa era o veículo que, por sua vez, trabalhou diuturnamente, trazendo informações sobre os combates através de correspondentes ou de transcrições de outros jornais sobre a situação na região do conflito, ou ainda, de divulgação de que começavam a aparecer os primeiros voluntários em outras províncias, tal como o editor do jornal Publicador Maranhense, João da Mata de Morais Rego, que dizia o seguinte:

Tenho o prazer de poder dar-lhes a noticia de que a Bahia não cede a nenhuma outra em brios e patriotismo. O Sr. Tenente-coronel Joaquim Maurício Ferreira offereceu-se com todos os seus oficiaes com 600 praças, de voluntários todos para defederem a honra e a dignidade da nação ${ }^{20}$.

A campanha de alistamento no Maranhão teve diferentes repercussões e manifestações, desde o alistamento no exército de linha a alistamentos no Corpo de Voluntários da Pátria que se ia formar, passando ainda por contribuições pecuniárias ou por prestação de serviços no lugar dos que se alistavam.

O governo provincial, de igual forma, tratava de informar a todos sobre o andamento do processo de formação dos corpos, quem estava organizando a tropa, como seria estruturado e como seria feito o alistamento. Podemos conferir essas informações no trecho a seguir:

\footnotetext{
${ }^{18}$ Publicador Maranhense, n. 23, 28 jan. 1865. p. 1. Biblioteca Pública Benedito Leite. São Luís, Maranhão. Seção de Periódicos, rolo 94.

${ }^{19}$ Publicador Maranhense, n. 23, 28 jan. 1865. p. 1. Biblioteca Pública Benedito Leite. São Luís, Maranhão. Seção de Periódicos, rolo 94.

20 Publicador Maranhense, n. 16, 20 jan. 1865. p. 1. Biblioteca Pública Benedito Leite. São Luís, Maranhão. Seção de Periódicos, rolo 94.
} 
Outros Tempos, vol. 18, n. 32, 2021, p. 278-297. ISSN: 1808-8031

O governo da província Palácio do Governo do Maranhão 24 de janeiro de 1865 - O presidente da província em virtude do decreto $n^{\circ} 3.371$ de 7 de janeiro ultimo, que manda organizar corpos de voluntários para o serviço da guerra [...]; resolve que os voluntários que se forem apresentando nos termos do dito decreto, formem um corpo de duas ou mais companhias [...]. A organização do Corpo é confiada ao capitão d'estado maior de $1^{\text {a }}$ Classe Luiz Eduardo de Carvalho, que se ofereceu voluntariamente para marchar para o sul. As companhias serão organizadas à proporção que se forem apresentando os voluntários, e oportunamente serão nomeados por esta presidência os mais officiaes, que a devem compor - Ambrosio Leitão da Cunha $^{21}$.

É interessante observar que, além da divulgação das providências para organizar as unidades, foi informado também que o oficial que se propôs a organizar os corpos se ofereceu voluntariamente para compor a força e ir para o teatro de operações.

A partir de janeiro, quando foi divulgado o decreto dos voluntários da pátria, as conclamações para o alistamento se intensificaram e partiram muitas vezes dos editores dos jornais, a ponto de se tornarem diárias.

Notícias sobre guardas nacionais que se alistavam voluntariamente também eram constantemente divulgadas. Assim o jornal Publicador Maranhense noticiou em 3 de março de 1865 que "[...] apresentaram-se voluntariamente para fazer parte dos dous corpos que devem destacar aqui, 10 guardas do $1^{\circ}$ batalhão e 20 do $2^{\circ}$ batalhão e os officiaes"22.

De todo modo, a primeira impressão causada pela guerra junto à população, ao que parece, foi a expectativa da vitória rápida, coberta de glórias, elemento fortemente acelerado pela busca de recuperação da honra e do território.

Nesse sentido, no momento em que o país passava por um processo forçado de formação de seu estado nacional, a imagem de uma guerra distante promoveria a identificação da sociedade brasileira com os objetivos traçados pelo governo, que eram o autorreconhecimento e a afirmação da nacionalidade junto ao seu povo e o reconhecimento perante as outras nações do respeito e da soberania nacional; pelo menos, parecia ser isso o que o governo imperial pensava, apesar das contradições que o Brasil possuía no tocante a sua sociedade, tradicionalmente escravocrata, pois reconhecia a escravidão como legítima. Mesmo diante desse contrassenso, é possível identificar a intenção do governo imperial de fazer o país ser reconhecido como uma nação forte mediante a condução de uma guerra. Hobsbawm nos indica que durante o século XIX havia três condições indispensáveis para um

\footnotetext{
${ }^{21}$ Publicador Maranhense, n. 51, 3 mar. 1865. p. 1. Biblioteca Pública Benedito Leite. São Luís, Maranhão. Seção de Periódicos, rolo 94.

22 Publicador Maranhense, n. 51, 3 mar. 1865. p. 2. Biblioteca Pública Benedito Leite. São Luís, Maranhão. Seção de Periódicos, rolo 94.
} 
Outros Tempos, vol. 18, n. 32, 2021, p. 278-297. ISSN: 1808-8031

povo ser reconhecido como uma nação e que essa ideia passava pela existência coletiva de povo. Uma dessas condições era a capacidade de fazer a guerra (HOBSBAWM, 1996, p. 49), levando-se em conta a organização desse povo em torno de um estado forte e que desse uma prova de capacidade para a conquista militar.

O jornal Publicador Maranhense, por ser o órgão oficial do governo, noticiava as decisões tomadas pelo presidente da província em nome do governo imperial, uma delas tratava da convocação de homens da Guarda Nacional (designação) ${ }^{23}$ e do recrutamento para o Exército.

Quanto ao recrutamento militar, desde a colônia havia se constituído num mecanismo de controle social, cuja eficácia foi diminuindo progressivamente após a abdicação em 1831. As variações entre uma maior ou menor atividade de recrutamento naquele momento não significavam preocupações por parte do governo com a contenção à vadiagem ou à desordem, mas com as necessidades militares em tempo de guerra: as revoltas nas províncias dos anos 1830 e início dos anos 1840, dentre elas a Balaiada; o conflito de 1851 a 1852, ou Guerra do Prata, para depor Juan Manuel de Rosas; a crise diplomática com a Grã Bretanha em 1863, desencadeada pela questão Christie; a intervenção no Uruguai em fins de 1864; e em proporções maiores, a Guerra do Paraguai entre 1864 e 1870, cujo ato de recrutamento voltaria a ser uma prática comum e se intensificaria ainda em fins de 1865 , sem falar da designação de guardas nacionais.

Assim, em pleno período da campanha de mobilização e com o grande afluxo de alistamentos, o expediente dos tempos de $\operatorname{paz}^{24}$ de se recrutar criminosos continuou, tanto que foi alvo de denúncias por parte do jornal Publicador Maranhense, lembrando que "[...] o recrutamento para o exército [...] não pode ser considerado como meio de reprimir e punir criminosos. Sendo, portanto, [...] criminoso [...] José Cypriano de Oliveira, e deve ser processado e punido na forma da lei e não assentar praça no exército, para o que de mais a mais não é hábil”25.

\footnotetext{
${ }^{23}$ A designação consistia na convocação nominal de Guardas Nacionais, que eram destacados para o serviço da Guerra, sobre o assunto ver: (DORATIOTO, 2002); sobre o voluntariado e a designação na província do Maranhão para a guerra do Paraguai, ver: (ARAÚJO, 2008).

${ }^{24}$ Durante a época de paz, o Exército lançava um edital de voluntariado, cuja responsabilidade era da polícia. Geralmente, o edital não era preenchido e, para completar, o efetivo da polícia recorria a detenções indiscriminadas de pessoas muito pobres ou à margem do sistema produtivo, ou simplesmente criminosos de todas as ordens. Em tempos de crise como a guerra contra o Paraguai, a demanda por soldados cresceu muito, e os primeiros tempos de voluntariado espontâneo havia cessado, fazendo o governo imperial recorrer novamente ao voluntariado forçado. Ver: (KRAAY, 1999).

${ }^{25}$ Publicador Maranhense, n. 52, 4 mar. 1865. p. 1. Biblioteca Pública Benedito Leite. São Luís, Maranhão. Seção de Periódicos, rolo 94.
} 
Outros Tempos, vol. 18, n. 32, 2021, p. 278-297. ISSN: 1808-8031

Nesse aspecto, os jornais também teriam significativa participação no processo de mobilização contra abusos no sistema de alistamento, que naqueles meses iniciais da Guerra contra o Paraguai, em 1865, ainda aconteciam, e não correspondiam ao discurso de unidade nacional propalado pelo estado imperial a favor do voluntariado.

\section{Direto da guerra para a província do Maranhão}

Em 3 de agosto de 1865, o então presidente da província do Maranhão, Lafayete Rodrigues Pereira, mandou avisar ao ministro dos negócios da justiça que seguia para a Corte a Brigada Expedicionária da Guarda Nacional do Maranhão, e que continuaria os esforços no sentido de enviar o número total de guardas nacionais que cabia à província do Maranhão, pois somente 586 praças foram embarcadas (DUARTE, 1981, p. 149).

O embarque da brigada maranhense foi acompanhado de uma imensa festa, amplamente divulgada pelos jornais. Mantendo-se como forte veículo de propaganda da guerra, o jornal Publicador Maranhense do dia 4 de agosto detalhou todos os pormenores da festa em honra da Guarda Nacional. Segundo o seu editor.

Desde as 6 horas da manhã começou a afluir ao quartel do Campo do Ourique um grande concurso de povo, ansioso de victoriar os cidadãos que vão verter o sangue em prol da honra nacional.

As 81,2 horas, por entre vivas acclamações, poz-se em marcha a brigada, acompanhada de uma imensa multidão de pessoas de todas as classes, entre as quaes notava-se a câmara municipal incorporada.

Desfilou pela rua do Sol, drigindo-se-á Igreja Cathedral, onde foi assistir ao santo sacrifício da missa e implorar a graça do Deus dos exércitos.

A rua do Sol desde o canto de São João, e a de Nazareth, até pouco antes de desembarcar no largo da Assembléia, achavam-se vistóriosamente decoradas. Em toda a sua extensão, viam-se, separados por curtas distancias, arcos de murta, embandeirados, e alguns entresachados de flores. Ao longo dos passeios estavam collocados pequenos mastros, pintados de verde, ornados de bandeiras, e unidos uma aos outros por festões de rama. O chão achava-se alastrado de folhas.

Essa bella decoração, devida aos nobres sentimentos dos moradores dessas ruas, nacionaes e estrangeiros, foi dirigida pelos Snrs. Capitão João Marcelino Romeu, Oséias, Frederico Guilherme de Araújo, o empresário da companhia dramática Vicente Pontes d'Oliveira e alguns de seus irmãos d'Arte.

Ao largo do Palácio havia um arco triumphal, levantado por ordem da Câmara Municipal. O Snr. José Joaquim Gomes Palmeira, encarregado desse trabalho, fel-o gratuitamente.

A rampa [de embarque do porto] foi também embandeirada pelo Snr Guarda mor interino Raymundo Ferreira Barbosa. 
Outros Tempos, vol. 18, n. 32, 2021, p. 278-297. ISSN: 1808-8031

As janelas regorgitavam de senhoras que derramavam flores sobre esses bravos e os saudavam com lenços $[\ldots]^{26}$.

Quando estourou o conflito, o Publicador Maranhense procurou dar relevo à guerra, não apenas noticiando sobre os acontecimentos do teatro de operações, mas publicando trechos de cartas e cartas inteiras dos combatentes que se encontravam na frente de batalha. Quando em fins de 1865 e início de 1866 a guerra começava a despertar incertezas por conta da demora em derrotar o Paraguai e, com a queda na sua popularidade, em razão das perdas de soldados, a publicação dessas missivas trazia aos leitores da província os sentimentos e expectativas de seus entes. Uma das correspondências de particulares publicada pelo Publicador Maranhense foi a de um marinheiro, endereçada aos seus familiares, em que relatava a grande expectativa que todos no Sul tinham com a esperada notícia da queda da fortaleza de Humaitá. Em seu texto dizia que:

[...] não faz idéia do alvoroço e alegria com que todo se dispõem a festejar o extraordinário bando - que no vem anunciar a queda de Humayta e o descerramento de par em par das portas da suspirada Assumpção! comprehende perfeitamente o inaudito prazer com que hei de narrar todos os episódios d'esse assombroso acontecimento ${ }^{27}$ ?

Ainda em 1866, o jornal Publicador Maranhense continuava a noticiar a guerra com grande enfoque nas correspondências, publicando cartas particulares, como a de outro guarda marinha maranhense, endereçada ao seu irmão, que residia em São Luís. O referido guarda participou de um dos combates e fazia parte da tripulação da canhoneira Ivai. O jornal preocupava-se, sobretudo, em relatar a ação de que participou. A carta foi escrita da província Argentina de Corrientes, uma das principais bases de operações das forças da Tríplice Aliança:

[...] Seguia a Ivahy, só águas acima, quando disse-nos o commandante que iamos reconhecer um vapor que mal se distinguiu. A commissão era arriscadissima, e até esse dia nenhum navio tinha desempenhado, só, alguma semelhante. Podia aquelle vapor ser uma negaça [ardil], e o que o fosse reconhecer cahir victima dos paraguayos $[\ldots]^{28}$.

\footnotetext{
${ }^{26}$ Publicador Maranhense, n. 175, 4 ago. 1865. p. 2. Biblioteca Pública Benedito Leite. São Luís, Maranhão. Seção de Periódicos, rolo 94.

27 Publicador Maranhense, n. 12, 16 jan. 1866. p. 1. Arquivo Público do Estado do Maranhão. São Luís, Maranhão. Seção de Periódicos.

${ }_{28}$ Publicador Maranhense, n. 3, 4 fev. 1866. p. 2. Arquivo Público do Estado do Maranhão. São Luís, Maranhão. Seção de Periódicos.
} 
Outros Tempos, vol. 18, n. 32, 2021, p. 278-297. ISSN: 1808-8031

No Publicador Maranhense também havia a preocupação de divulgar sobre o alistamento de libertos. Assim, em agosto de 1868, informava sobre a situação dos libertos que assentavam praça na armada ou no exército:

[...] desde que chegou a esta Província ordem para serem libertados por conta da Fazenda e terem praça no Exército e na Armada, escravos que tivessem aptidão para aquelle serviço tiveram liberdade, foram alistados e seguiram daqui a Corte 422 libertos sendo 140 para o Exército e 282 para a Armada $^{29}$.

Nos primeiros meses da guerra contra o Paraguai, a atuação dos jornais foi de fundamental importância para alavancar a opinião pública e angariar apoio para formação de contingentes. O papel do Publicador Maranhense continuaria a ser preponderante, mesmo com a alternância no poder da província em 1868, entre o partido liberal e a ascensão dos conservadores. Suas páginas continuaram a servir ao governo. A sua influência marcaria permanentemente o jornalismo no Maranhão ao longo de pelo menos mais duas décadas, quando finalmente se uniria ao periódico $O$ Paiz, para formar um único periódico com o mesmo nome de $O$ Paiz, mas, a partir de então, um jornal político. Entretanto, essa perspectiva é uma outra história.

Com a subida ao poder dos conservadores, a situação na província mudou, mas a primazia do jornal continuava. A alternância das forças políticas não tirou do jornal e de seus editores o apoio a causa da guerra, mas as críticas, que antes eram dirigidas pelos conservadores aos liberais, naquele momento haviam mudado de direção, e isso era profundamente observado nos demais jornais, na província e nas demais províncias do Império.

\section{Conclusão}

Ao longo da guerra, é inegável que o papel dos jornais na construção do processo de divulgação e de propaganda do conflito foi fundamental para assegurar ao exército imperial a formação contínua de seus contingentes.

O custo da guerra tem sido mensurado por diversos estudos ao longo dos anos e, como o tema ainda é delicado, suscita diferentes balanços. Auspiciosamente, a possibilidade de se estudar os diferentes componentes de entendimento sobre o assunto, como o papel dos jornais, também tem sido desenvolvida paralelamente, tal como outras questões, entre as quais

${ }^{29}$ Publicador Maranhense, n. 182, 11 ago. 1868. p. 3. Arquivo Público do Estado do Maranhão. São Luís, Maranhão. Seção de Periódicos. 
Outros Tempos, vol. 18, n. 32, 2021, p. 278-297. ISSN: 1808-8031

o impacto nas relações internacionais, a construção das identidades nacionais na América Latina e a consciência dessas identidades.

Assim, a imprensa brasileira e maranhense, à época da Guerra do Paraguai, pode ser considerada como uma fonte muito rica de símbolos que visava alimentar o imaginário brasileiro e fazer criar uma ideia em torno de personalidades políticas e militares, tanto brasileiras quanto paraguaias, desse período, tanto as exaltando, como as criticando.

Buscar o trabalho da imprensa no período da Guerra do Paraguai é tarefa, além de instigante, bastante rica e envolvente, que permite ao pesquisador encontrar inúmeros caminhos entre editorias e notícias que avalizavam a guerra.

Através da análise sobre o jornal o Publicador Maranhense, verificou-se que as notícias da guerra eram apresentadas de maneira variada, seus redatores falavam das vitórias no campo de batalha com entusiasmo. Em seus editoriais e notas demonstravam o seu comprometimento com o governo imperial e provincial.

Apesar dos embates de ideias e de palavras que existiam entre os demais periódicos da época, e que representavam as diferentes agremiações políticas, o Publicador Maranhense mantinha-se firme na construção de um sentido que legitimava a guerra.

Percebe-se ainda que o jornal era dotado de uma escrita carregada de erudição, seus editoriais versavam com alusão a arquétipos da História Clássica, fazendo referências a governantes de outros países. Em suas páginas, sobretudo nos editoriais, os articulistas e jornalistas usavam do argumento da autoridade contra o grande inimigo do país, o presidente do Paraguai, Solano Lopez. Subentende-se, pois, que o jornal era direcionado a um público relativamente erudito e culto que conhecia história e política. A maioria dos editoriais do Publicador Maranhense nos leva a conhecer outras implicações da Guerra do Paraguai através de um viés nacionalista, o que contribuía para fortalecer o regime monárquico.

A leitura sobre a Guerra do Paraguai, a partir de escrita de o Publicador Maranhense, permite ao leitor delinear o contorno dos acontecimentos da época, no Brasil e em muitas nações do mundo, pois noticiava sobre os conflitos e sobre a política internacional. Este artigo procurou mostrar um quadro sobre a construção da Guerra do Paraguai através da escrita de um jornal e, nessa escrita, pode se perceber que paralelo à união com o regime político, verificou-se ainda a existência de uma absoluta liberdade de expressão, com certa ausência de censura sobre o exercício da atividade jornalística. Essa situação de fato seria, na opinião da época, em razão da ação pessoal do imperador Pedro II que, por seguidas vezes, recusou-se a promulgar leis ou decretos que restringissem a liberdade de imprensa no Brasil. 
Outros Tempos, vol. 18, n. 32, 2021, p. 278-297. ISSN: 1808-8031

\section{Referências}

\section{Documentos}

Publicador Maranhense, n. 1, 2 jan. 1865. Biblioteca Pública Benedito Leite. São Luís, Maranhão. Seção de Periódicos, rolo 94.

Publicador Maranhense, n. 16, 20 jan. 1865. Biblioteca Pública Benedito Leite. São Luís, Maranhão. Seção de Periódicos, rolo 94.

Publicador Maranhense, n. 17, 21 jan. 1865. Biblioteca Pública Benedito Leite. São Luís, Maranhão. Seção de Periódicos, rolo 94.

Publicador Maranhense, n. 18, 23 jan. 1865. Biblioteca Pública Benedito Leite. São Luís, Maranhão. Seção de Periódicos, rolo 94.

Publicador Maranhense, n. 23, 28 jan. 1865. Biblioteca Pública Benedito Leite. São Luís, Maranhão. Seção de Periódicos, rolo 94.

Publicador Maranhense, n. 32, 9 fev. 1865. Biblioteca Pública Benedito Leite. São Luís, Maranhão. Seção de Periódicos, rolo 94.

Publicador Maranhense, n. 51, 3 mar. 1865. Biblioteca Pública Benedito Leite. São Luís, Maranhão. Seção de Periódicos, rolo 94.

Publicador Maranhense, n. 52, 4 mar. 1865. Biblioteca Pública Benedito Leite. São Luís, Maranhão. Seção de Periódicos, rolo 94.

Publicador Maranhense, n. 175, 4 ago. 1865. Biblioteca Pública Benedito Leite. São Luís, Maranhão. Seção de Periódicos, rolo 94.

Publicador Maranhense, n. 3, 4 fev. 1866. Arquivo Público do Estado do Maranhão. São Luís, Maranhão. Seção de Periódicos.

Publicador Maranhense, n. 10, 13 jan. 1866. Arquivo Público do Estado do Maranhão. São Luís, Maranhão. Seção de Periódicos.

Publicador Maranhense, n. 12, 16 jan. 1866. Arquivo Público do Estado do Maranhão. São Luís, Maranhão. Seção de Periódicos.

Publicador Maranhense, n. 182, 11 ago. 1868. Arquivo Público do Estado do Maranhão. São Luís, Maranhão. Seção de Periódicos.

\section{Bibliografia}

ARAÚJO, Johny Santana de. A mobilização, o voluntariado e formação dos corpos de voluntários da pátria no Maranhão para a guerra do Paraguai, 1865. Revista do Instituto Histórico e Geográfico Brasileiro, ano 169, n. 439, p. 313-338, 2008. 
Outros Tempos, vol. 18, n. 32, 2021, p. 278-297. ISSN: 1808-8031

ARAÚJO, Johny Santana de. El Imperio de Brasil, los estados platinos en el prólogo de la guerra de 1865", Caravelle [on line], n. 108, p. 135-148, 2017. DOI:

https://doi.org/10.4000/caravelle.2338. Disponível em:

http://journals.openedition.org/caravelle/2338. Acesso em: 22 mar. 2021.

BANDEIRA, Luís. A. Moniz. A expansão do Brasil e a formação dos estados na Bacia do Prata: Argentina, Uruguai e Paraguai - da colonização à Guerra da Tríplice Aliança. 4. ed. Rio de Janeiro: Civilização Brasileira, 2012.

BERNARDO, Cristiane Hengler Corrêa; LEAO, Inara Barbosa. Formação do jornalista contemporâneo: a história de um trabalhador sem diploma. Rev. Bras. Hist., São Paulo, v. 33, n. 65, p. 337-358, 2013. DOI: https://doi.org/10.1590/S0102-01882013000100014. Disponível em: http://www.scielo.br/scielo.php?script=sci_arttext\&pid=S010201882013000100014\&lng=en\&nrm=iso. Acesso em: 22 mar. 2021.

DORATIOTO, Francisco Fernando Monteoliva. Maldita Guerra: nova história da Guerra do Paraguai. São Paulo: Companhia das Letras, 2002.

DUARTE, Paulo de Queiroz. Os voluntários da Pátria na Guerra do Paraguai. Rio de Janeiro: Biblioteca do Exército, 1981.

GANDIA, Leonardo dos Reis. A política ao fio da espada: Caxias e a consolidação dos interesses brasileiros no Rio da Prata (1842-1852). São Paulo: Intermeios; FAPESP, 2019.

GRAHAM, Richard. Os fundamentos da ruptura de relações diplomáticas entre o Brasil e a Grã-Bretanha em 1863: "A questão Christie". Revista de História da USP, v. 24, n. 49, p. 117-138, 1962. DOI: https://doi.org/10.11606/issn.2316-9141.rh.1962.121593. Disponível em: https://www.revistas.usp.br/revhistoria/article/view/121593/118496. Acesso em: 22 abr. 2021.

HOBSBAWM, Eric J. Nações e nacionalismo desde 1780: programa, mito e realidade. 2. ed. São Paulo: Paz e Terra, 1996.

KRAAY, Hendrik. Repensando o recrutamento militar no Brasil Imperial. Diálogos: Revista do Departamento de História da Universidade Estadual de Maringá, Maringá, PR, v. 3, n. 3, p. 113-151, 1999. Disponível em:

https://periodicos.uem.br/ojs/index.php/Dialogos/article/view/37540. Acesso em: 22 abr. 2021.

LEAL, Antônio Henriques. Pantheon Maranhense: ensaios biográficos dos Maranhenses ilustres já falecidos. Rio de Janeiro: Alhambra, 1987. t. 1.

LISBOA, João F. Jornal de Timon: eleições na Antigüidade, eleições na Idade Média, eleições na Roma Católica, Inglaterra, Estados Unidos, França, Turquia, partidos e eleições no Maranhão. Brasília: Senado Federal, 2004.

MAESTRI, Mário. A Guerra contra o Paraguai: história e historiografia: da instauração à restauração historiográfica [1871-2002]. Nuevo Mundo Mundos Nuevos [on line], Colloques, mis en ligne le 27 mars 2009. DOI: https://doi.org/10.4000/nuevomundo.55579. Disponível em: https://journals.openedition.org/nuevomundo/55579. Acesso em: 21 mar. 2021. 
Outros Tempos, vol. 18, n. 32, 2021, p. 278-297. ISSN: 1808-8031

MATTOS, Ilmar Rohloff de. O tempo Saquarema. 5. ed. São Paulo: HUCITEC, 2004.

MORSE, Richard. Formação histórica de São Paulo, da comunidade à metrópole. São Paulo: Difusão Europeia do Livro, 1970.

PAULA, Edgley Pereira de. Guerra na imprensa ou imprensa de guerra?: a imprensa brasileira nos campos de batalha da Guerra do Paraguai. São Paulo: Scortecci, 2020.

RAMOS, Clovis. Opinião pública maranhense: jornais antigos do Maranhão 1831 - 1860. São Luís: SIOGE, 1992.

RÉ, Henrique Antônio. Um agente do Império brasileiro em Londres: William Henry Clark e o fim da política da escravidão saquarema. Antíteses, [s.l.], v. 11, n. 22, p. 727-748, jan. 2019. DOI: http://dx.doi.org/10.5433/1984-3356.2018v11n22p727. Disponível em:

http://www.uel.br/revistas/uel/index.php/antiteses/article/view/34058/25514. Acesso em: 22 abr. 2021.

REIS, Flavio. Grupos políticos e estrutura oligárquica no Maranhão. São Luís: Unigraf, 2007.

SALLES, Ricardo. Guerra do Paraguai: escravidão e cidadania na formação do exército. São Paulo: Paz e Terra, 1990.

SERRA, Joaquim. Sessenta anos de jornalismo: a imprensa no Maranhão. São Paulo: Siciliano, 2001.

SILVEIRA, M. C. Os múltiplos papéis do jornalismo brasileiro na guerra contra o Paraguai. Historiae, [s. l.], v. 5, n. 1, p. 213-236, 2014. Disponível em:

https://periodicos.furg.br/hist/article/view/4812. Acesso em: 23 mar. 2021.

SOARES, Pedro Paulo. A guerra da imagem: iconografia da guerra do Paraguai na imprensa ilustrada fluminense. 2003. Dissertação (Mestrado em História Social) - Universidade Federal do Rio de Janeiro, Rio de Janeiro, 2003.

VIVEIROS, Jerônimo. História do Comércio do Maranhão 1612 - 1895. São Luís: Associação Comercial, 1954.

WHIGHAM, Thomas. The Paraguayan War: causes and early conduct. 2nd edition. Calgary: University of Calgary Press, 2018. 